\title{
Sistem Informasi Geografis Pencarian Lokasi Wisata Kuliner Terdekat di Kota Mataram Berbasis Website
}

\author{
(Website-based Geographic Information System for Searching Nearby \\ Culinary Location in Mataram City)
}

Julianto Eko Prasetyo, IBK Widiartha, Moh. Ali Albar

Prodi Teknik Informatika, Fakultas Teknik, Universitas Mataram

Jl. Majapahit 62, Mataram, Lombok, NTB-INDONESIA

Email: ayanaeka@gmail.com,widi@unram.ac.id,mohalialbar@unram.ac.id

\begin{abstract}
Culinary development in the area of Mataram city at the moment is growing rapidly. Culinary tour offered varies greatly among them is the famous Lombok's cuisine with a taste of spiciness. The constraints experienced by travellers who have recently visited the city of Mataram is the difficulty to find a desired culinary location. Geographic information system for searching the location of nearby culinary Mataram city in this case can help make it easier for tourists to know the mapping of the location of the culinary tourism in the area of the city of Mataram. Web-based geographic information system is built by using the concept of MVC with directions from the position of travellers to culinary tour you want. The calculation to determine the distance of the location of culinary positions with travelers using the haversine formula. Based on a test that is done to the user, the average percentage of answers given by respondents agreed by $50 \%$ and the average percentage of answer strongly agree of $44.6 \%$ stating that geographic information systems this can already detect the locations of your users are able to display the distance between the user location information with location of culinary around, it can display the route to culinary tourism is selected and has the look of an attractive and easy to use.
\end{abstract}

Key Words : Culinary, Haversine, Geographic Information System, MVC.

\section{PENDAHULUAN}

Potensi wisata yang terdapat di daerah pulau Lombok pada saat ini mulai banyak dilirik oleh para wisatawan lokal maupun mancanegara karena jenis obyek wisata yang ditawarkan di pulau Lombok sendiri beraneka ragam seperti wisata alam, wisata religi, wisata budaya dan yang tidak kalah pamornya adalah wisata kuliner.

Perkembangan lokasi wisata kuliner di daerah Mataram semakin banyak, hal ini menyebabkan para penikmat kuliner khususnya yang berasal dari luar daerah Mataram sulit untuk mencari lokasi wisata kuliner sesuai dengan yang diinginkan. Selama ini para wisatawan penikmat kuliner menggunakan cara manual untuk mencari lokasi kuliner, yaitu dengan cara berkunjung secara langsung maupun hanya dengan melihat di media sosial seperti instagram, facebook dan blogspot. Bagi para wisatawan cara manual yang dilakukan tersebut kurang efektif karena mengahabiskan banyak waktu dan informasi alamat untuk menuju lokasi kuliner kurang memadai.

Berdasarkan permasalahan yang telah dipaparkan diatas maka diperlukan sebuah sistem informasi geografis yang mampu menampilkan dan menyajikan informasi tentang lokasi tempat kuliner (restoran, cafe maupun rumah makan tradisional) yang dilengkapi dengan informasi lokasi dengan jarak terpendek atau lokasi terdekat dengan para user (wisatawan) berada. User dapat memilih kategori wisata kuliner yang diinginkan untuk pencarian lokasi wisata kuliner terdekat dan user juga dapat memberikan review atau ulasan tentang lokasi wisata kuliner yang telah dikunjungi dengan bantuan sistem informasi geografis wisata kuliner terdekat kota Mataram ini. Lokasi wisata kuliner terdekat yang akan ditampilkan pada sistem ini berupa marker yang terdapat di peta yang telah disedikan oleh Google Maps. Sistem yang akan dibangun dapat memberikan petunjuk arah untuk menuju lokasi wisata kuliner yang dituju. Sistem ini juga akan menampilkan informasi pada info window 
berupa alamat, nomor telepon dan nama dari wisata kuliner yang dituju.

\section{TINJAUAN PUSTAKA}

Pada penelitian terdahulu yang berjudul Peta Rekomendasi Pariwisata dan Kuliner Kabupaten Semarang dengan Metode Pencarian Terdekat Dijkstra bertujuan untuk mempermudah wisatawan asing maupun lokal dalam merencanakan rute pariwisata maupun lokasi kuliner yang terdekat dari tujuan mereka. Sistem ini dalam pencarian rute terdekat user menentukan lokasi awal dan tujuan secara manual. Informasi yang ditampilkan hanya jalur terdekat untuk menuju ke daerah tujuan dan tidak menampilkan informasi lainnya yang menunjang dari lokasi pariwisata maupun lokasi kuliner. Fitur yang ditawarkan pada sistem informasi ini masih sangat kurang[1].

Pada penelitian yang berjudul Penerapan Jquery Mobile dan PHP Data Object Pada Aplikasi Pencarian Lokasi Tempat Ibadah di Yogyakarta bertujuan untuk mencari lokasi ibadah terdekat. Pembangunan aplikasi ini berbasis mobile. Daerah cakupan pada aplikasi ini pada daerah Yogyakarta. Fitur petunjuk arah untuk menuju tempat ibadah tidak ditambahkan dalam aplikasi ini, hanya memberikan informasi lokasi berupa marker pada maps[2].

\section{METODE PENELITIAN}

Metodologi yang digunakan pada implementasi sistem informasi geografis untuk menentukan wisata kuliner terdekat adalah model Waterfall. Model Waterfall dapat dilihat pada Gambar 1.

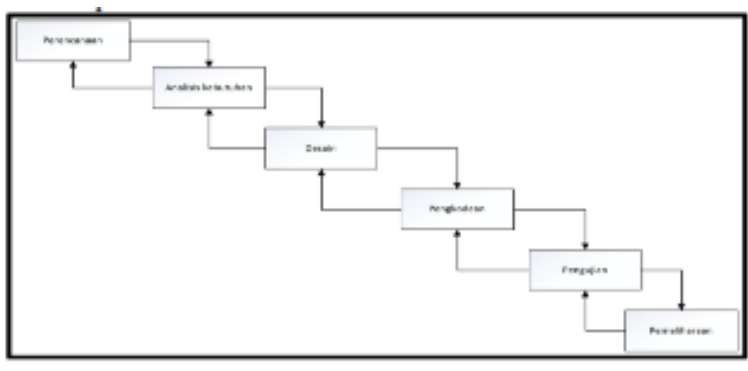

Gambar 1. Model Waterfall

Metode pengembangan sistem sekuensial linier atau yang sering disebut dengan siklus kehidupan klasik atau model air terjun (waterfall model) memberikan sebuah pendekatan pengembangan sistem yang sistematik dan sekuensial, dimulai pada fase perencanaan sistem, analisis, desain, kode, pengujian dan pemeliharaan.
Langkah awal dalam penelitian ini adalah pengumpulan data dilanjutkan dengan tahap analisis kebutuhan, perancangan sistem, pembangunan sistem dan uji coba. Pada model waterfall ini mengusulkan sebuah pendekatan kepada pengembangan perangkat lunak yang sistematik dan sekuensial yang mulai pada tingkat dan kemajuan sistem pada sebuah pengumpulan data, analisis kebutuhan, perancangan sistem, pembangunan sistem dan uji coba. Diagram alir penelitian dapat dilihat pada Gambar 2.

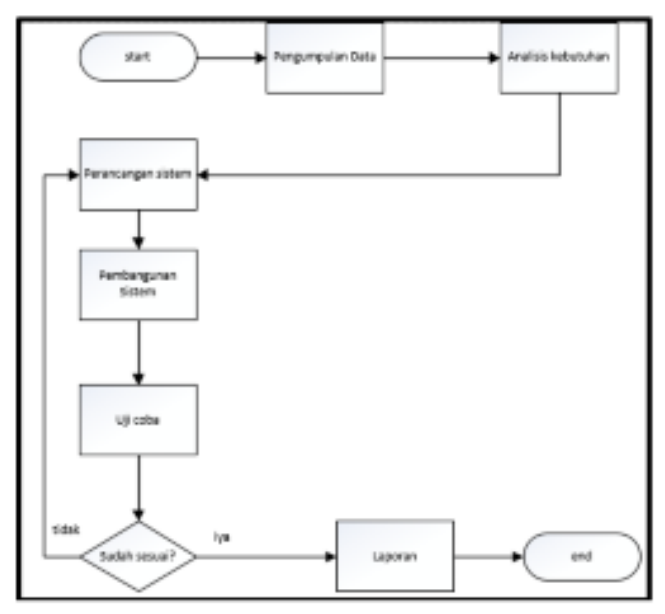

Gambar 2. Blok diagram sistem

\section{B. Tahapan Perancangan Sistem}

Tujuan utama dari perancangan sistem adalah memberikan gambaran perancangan sistem yang akan dibangun atau dikembangkan, serta untuk memahami alur informasi proses dalam sistem. Tahapan yang akan dilakukan dalam perancangan sistem:

1) Rancangan Arsitektur Sistem

2) Rancangan Proses

3) Rancangan Basis Data

4) Rancangan user Interface

C. Arsitektur Sistem

\section{A. Diagram Alir Penelitian}




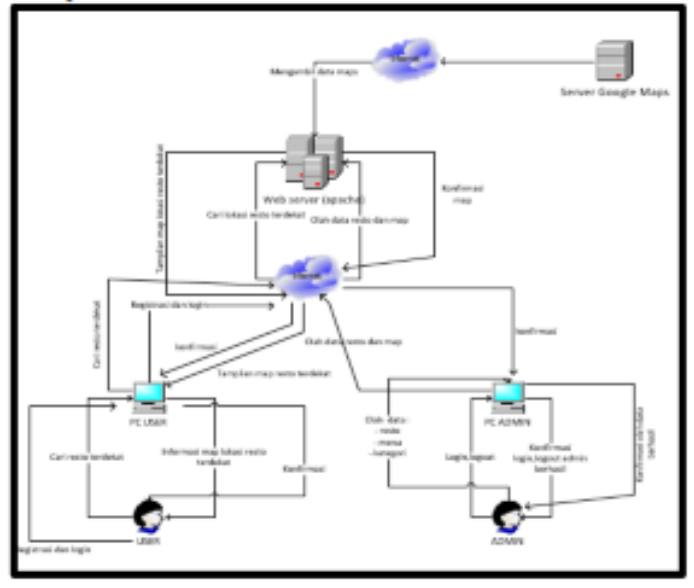

Gambar 3. Arsitektur Sistem

Sistem ini dibangun untuk memberikan informasi tentang lokasi wisata kuliner terdekat dari posisi user berada melalui media internet. Lokasi wisata kuliner divisualisasikan dalam bentuk peta yang terdiri dari data wisata kuliner di kota Mataram dengan bentuk marker. Sistem ini juga dapat menampilkan perbesaran dan pengecilan peta berdasarkan kategori yang dipilih. Sistem ini pun dapat mengembalikan ukuran peta semula sesuai dengan skala. Bentuk umum dari arsitektur ini dapat dilihat pada Gambar 3.

\section{Use Case Diagram}

Tujuan pemodelan use case ini untuk mendapatkan dan menganalisis informasi persyaratan yang cukup untuk mempersiapkan model yang mengkomunikasikan hal yang diperlukan dari perspektif pengguna, tetapi bebas dari detail spesifik tentang cara kerja sistem yang akan dibangun dan diimplementasikan. Use case sistem dapat dilihat pada Gambar 4.

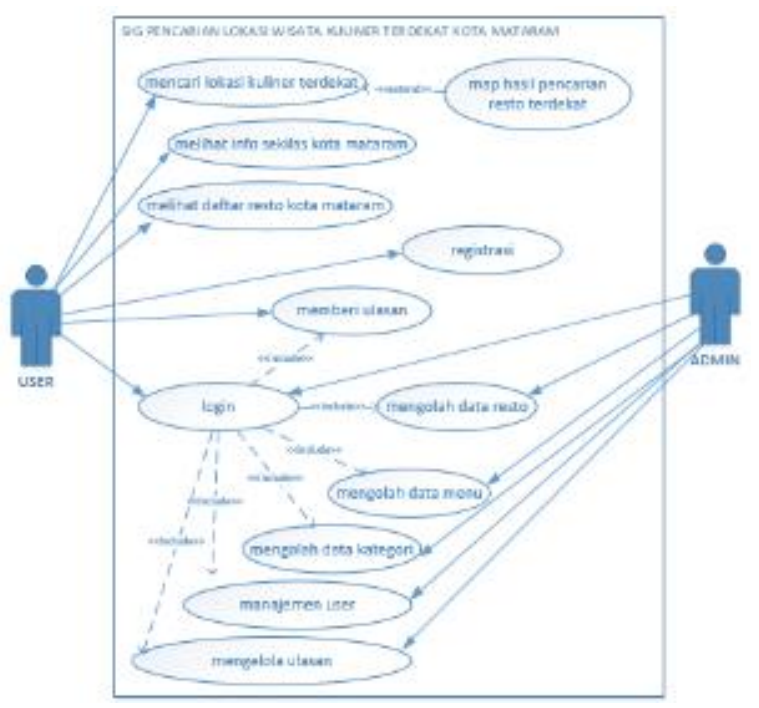

Gambar 4. Use Case Diagram

\section{E. Rancangan ERD}

Entity-Relationship Diagram (ERD) merupakan model yang berisi komponen-komponen Himpunan Entitas dan Himpunan Relasi yang masing-masing dilengkapi dengan atribut-atribut yang merepresentasikan seluruh fakta dari dunia nyata [3].

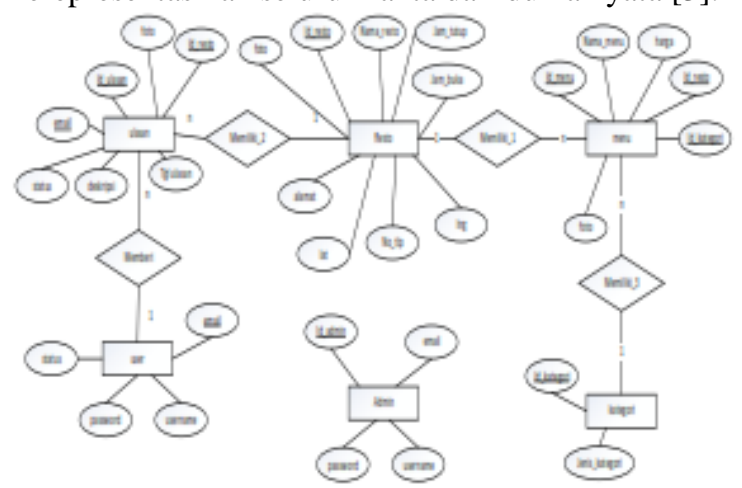

Gambar 5. Diagram ER

Dalam sistem yang dibuat terdapat tabel resto, tabel menu, tabel kategori tabel admin, tabel user dan tabel ulasan. Rancangan Diagram ER pada sistem dapat dilihat pada Gambar 5.

\section{F. Rancangan Site Map}

Antarmuka atau yang lebih dikenal sebagai user interface adalah sebuah media yang menghubungkan manusia dengan komputer agar dapat saling berinteraksi. Sebelum merancang antarmuka dari semua form pada website, maka untuk lebih memudahkan dalam perancangan akan dijelaskan terlebih dahulu struktur menu atau site map dari sistem. Rancangan site map user dapat dilihat pada Gambar 6.

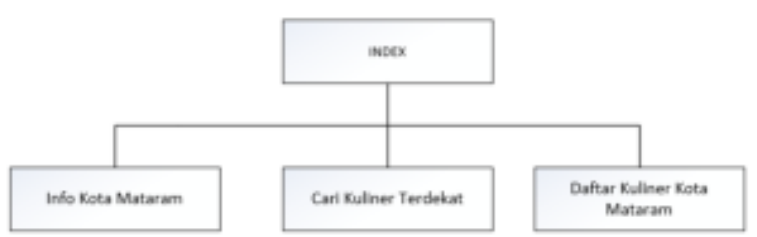

Gambar 6. Site map user

\section{G. Radius Pencarian}

Rumus haversine adalah persamaan yang penting pada navigasi, memberikan jarak lingkaran besar antara dua titik pada permukaan bola (Bumi) berdasarkan bujur dan lintang. Penggunaan rumus ini mengasumsikan pengabaian efek ellipsoidal, cukup akurat untuk sebagian besar perhitungan. Rumus ini digunakan untuk melakukan perhitungan jarak radius 
antara lokasi user dengan lokasi wisata kuliner. Berikut adalah rumus haversine:

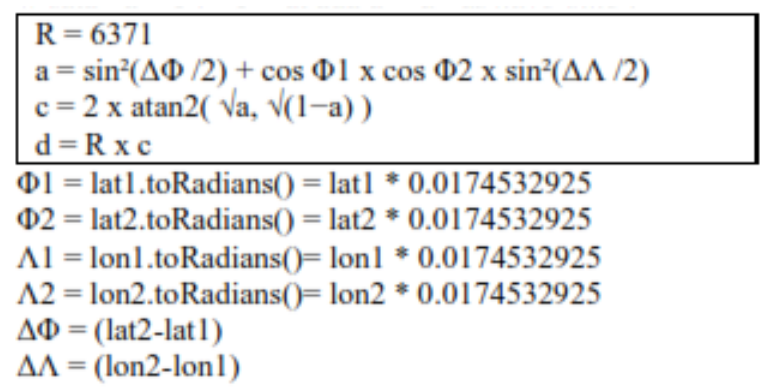

Keterangan :

$$
\begin{array}{ll}
\mathrm{R} & =\text { jari-jari bumi sebesar } 6371(\mathrm{~km}) \\
\Phi & =\text { latitude } \\
\Lambda & =\text { longitude } \\
\Delta \Phi & =\text { besaran perubahan latitude } \\
\Delta \Lambda & =\text { besaran perubahan longitude } \\
\mathrm{c} & =\text { kalkulasi perpotongan sumbu } \\
\mathrm{d} & =\text { jarak }(\mathrm{Km}) \\
1 \text { derajat } & =0.0174532925 \text { radian }
\end{array}
$$

Setiap sudut dirubah dalam bentuk radian untuk dimasukan kedalam fungsi trigonometri[4].

\section{IMPLEMENTASI SISTEM}

Proses implementasi dari perancangan sistem informasi geografis pencarian lokasi kuliner terdekat di Kota Mataram yang dilakukan pada bab sebelumnya akan dijelaskan pada bab ini. Dalam perhitungan jarak dari posisi user menuju lokasi kuliner terdekat dari posisinya menggunakan formulasi haversine. Para wisatawan yang berada di kota Mataram dapat menggunakan sistem informasi geografis ini dalam melakukan pencarian lokasi wisata kuliner terdekat dari posisinya, untuk pencarian lokasi kuliner dapat dipilih berdasarkan kategori menu yang diinginkan oleh pengunjung dan pengunjung dapat menentukan radius dalam pencarian lokasi kuliner yang diinginkan. Sistem dapat memberikan petunjuk rute untuk menuju lokasi kuliner yang diinginkan. Pengunjung juga dapat melihat serta memberikan ulasan tentang lokasi kuliner yang terdapat pada sistem.

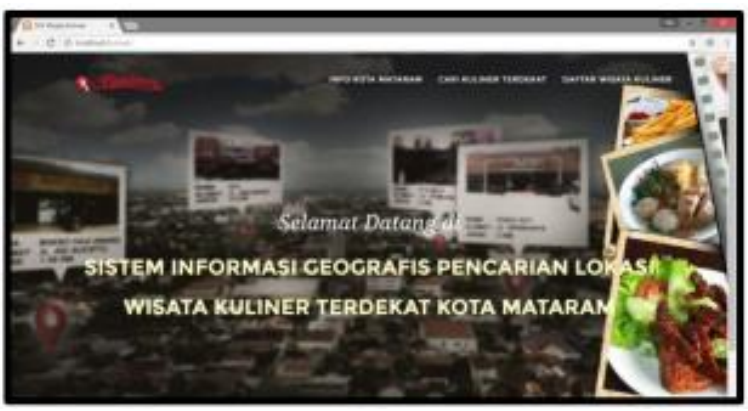

Gambar 7. Interface halaman utama

Gambar 7 merupakan halaman utama terdapat top menu yang terdiri info kota Mataram, cari kuliner terdekat dan daftar wisata kuliner. User dapat memilih info kota Mataram untuk membaca tentang sejarah kota Mataram. User dapat memilih menu cari kuliner terdekat untuk melakukan pencarian lokasi kuliner terdekat serta user dapat memilih menu daftar wisata kuliner untuk melihat daftar lokasi wisata kuliner yang terdapat di daerah kota Mataram.

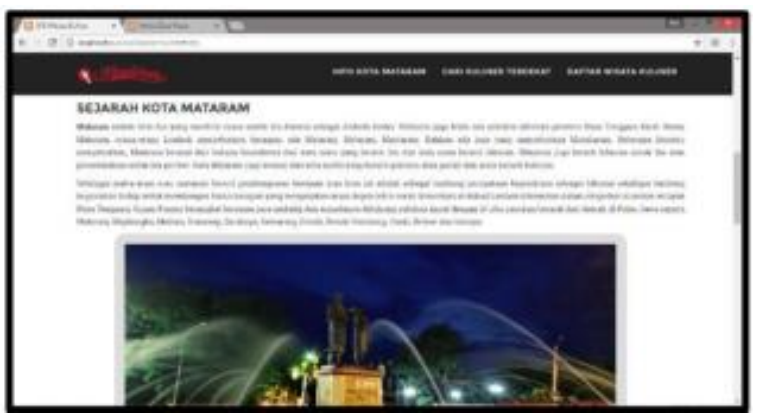

Gambar 8. Halaman info kota Mataram

Gambar 8 merupakan tampilan halaman info kota Mataram yang menyajikan informasi tentang sejarah singkat berdirinya kota Mataram.

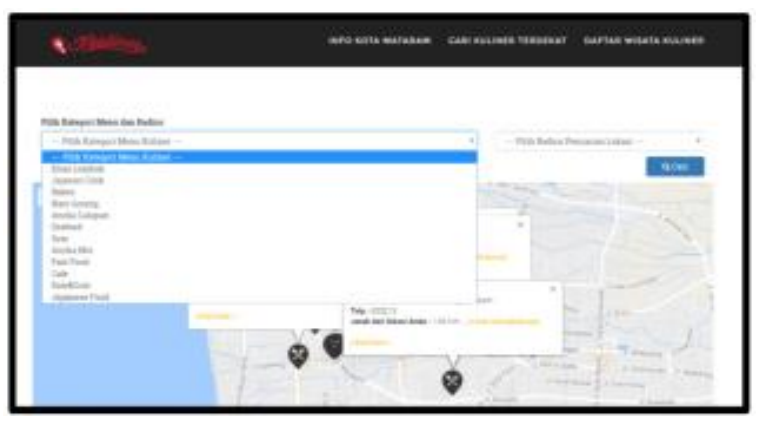

Gambar 9. Halaman cari kuliner terdekat pilih kategori

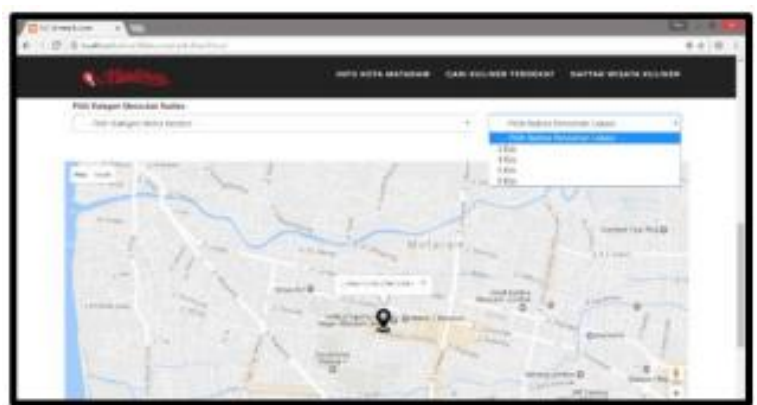

Gambar 10. Halaman cari kuliner terdekat pilih radius

Proses pencarian lokasi wisata kuliner terdekat dapat dilakukan pada halaman cari kuliner terdekat, sebelum 
melakukan pencarian lokasi wisata kuliner, user terlebih dahulu menentukan kategori menu dan radius pencarian yang telah tersedia pada sistem. Tampilan untuk memilih kategori menu dapat dilihat pada Gambar 9 dan tampilan untuk menentukan radius pencarian dapat dillihat pada Gambar 10.

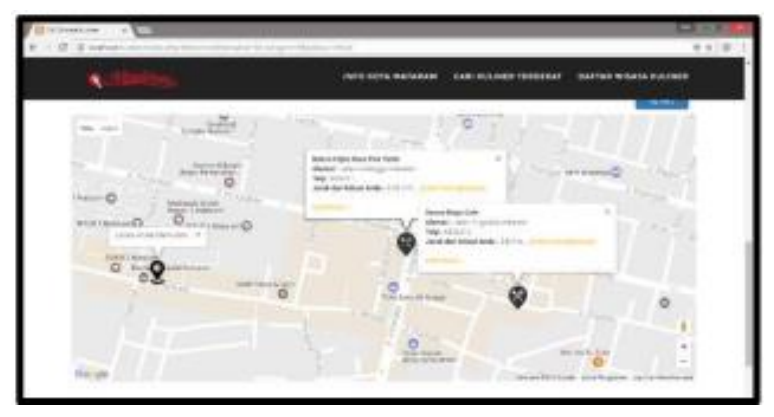

Gambar 11. Halaman cari kuliner terdekat hasil pencarian

Gambar 11 merupakan tampilan hasil pencarian lokasi wisata kuliner terdekat. Hasil pencarian di representasikan dalam bentuk marker pada map dan disediakan infowindow yang berisi informasi lokasi kuliner.

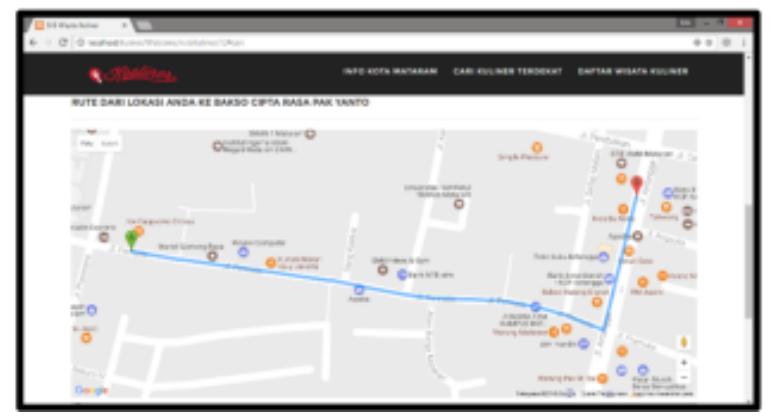

Gambar 12. Halaman cari kuliner terdekat lihat rute

Gambar 12 merupakan tampilan lihat rute yang menunjukan arah kepada user untuk menuju lokasi wisata kuliner yang akan dituju.

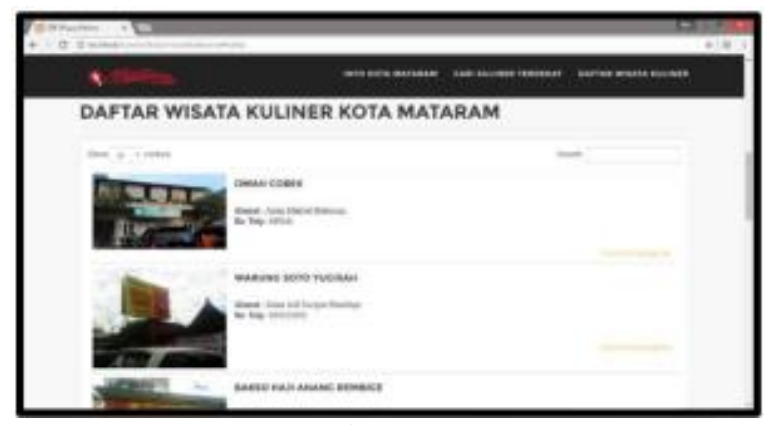

Gambar 13. Halaman daftar wisata kuliner
Gambar 13 merupakan tampilan dari halaman daftar kuliner. Halaman ini menyajikan daftar wisata kuliner yang terdapat di kota Mataram.

Setelah melakukan pengimplementasian sistem maka selanjutnya yang dilakukan adalah pengujian sistem. Pengujian selanjutnya adalah pengujian kuesioner yang dilakukan dengan menyebar form kuesioner pada 30 responden yang digunakan untuk mengukur kualitas sistem dari sisi pengguna. Representasi grafik dari keseluruhan hasil pengujian kuesioner dapat dilihat pada Gambar 14.

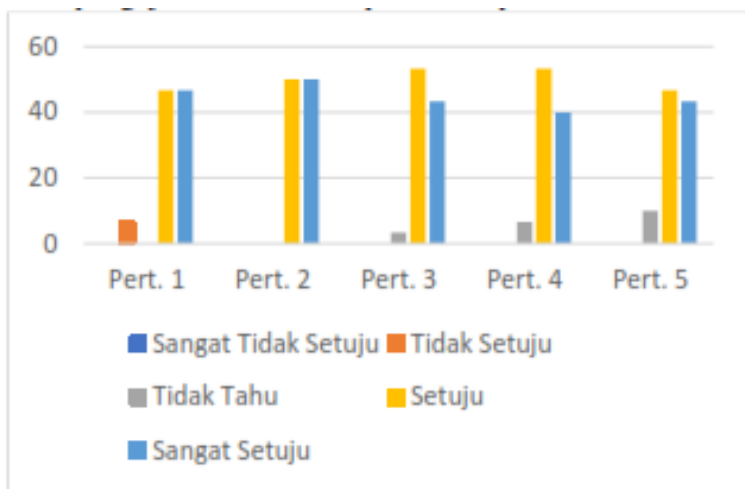

Gambar 14. Grafik persentase jawaban responden.

Berikut merupakan daftar pertanyaan yang diajukan pada responden:

1) Apakah lokasi anda dapat dideteksi dengan benar oleh sistem?

2) Apakah sistem dapat menampilkan jarak antara lokasi anda dengan lokasi kuliner sekitar anda?

3) Apakah sistem dapat memberikan rute perjalanan menuju lokasi wisata kuliner yang anda pilih?

4) Apakah tampilan dan desain pada sistem ini menarik?

5) Apakah sistem ini mudah digunakan?

Hasil dari perhitungan rata-rata keseluruhan jawaban responden terhadap pertanyaan yang diajukan dapat dilihat pada Gambar 7 berikut. 


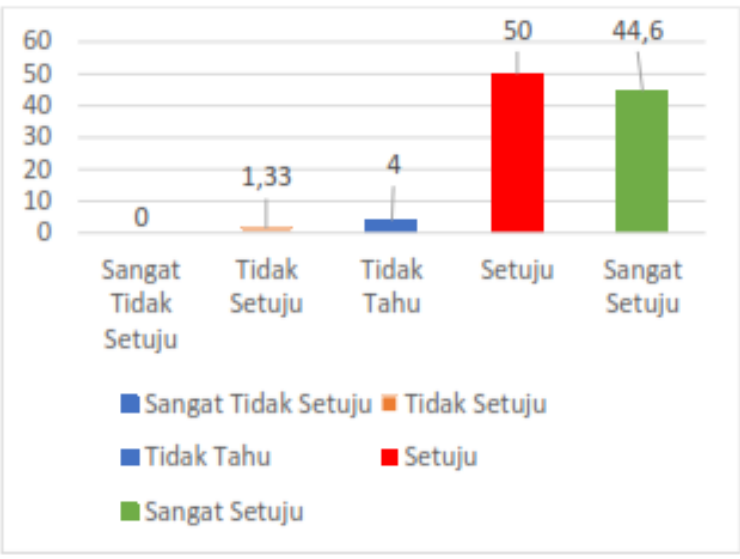

Gambar 15. Grafik persentase rata-rata jawaban responden.

Dari Gambar 15 dapat disimpulkan bahwa persentase rata-rata jawaban setuju yang diberikan oleh responden sebesar $50 \%$ dan persentase rata-rata jawaban sangat setuju sebesar 44,6 \% menyatakan bahwa sistem informasi geografis ini sudah dapat mendeteksi lokasi keberadaan user, sudah mampu menampilkan informasi jarak antara lokasi user dengan lokasi kuliner sekitar, sudah dapat menampilkan rute perjalanan menuju lokasi wisata kuliner yang dipilih serta memilki tampilan yang menarik serta mudah digunakan.

\section{KESIMPULAN DAN SARAN}

\section{A. Kesimpulan}

Kesimpulan yang didapatkan dari implementasi sistem informasi geografis pencarian lokasi wisata kuliner terdekat di kota Mataram adalah sebagai berikut:

1) Sistem dpat menampilkan jarak pada infowindow antara posisi user dengan lokasi kuliner yang berada disekitar user.

2) Sistem dapat menampilkan data lokasi kuliner berdasarkan kategori menu dan radius lokasi kuliner yang dipilih oleh user.

3) Berdasarkan hasil uji coba yang telah dilakukan pada $u s e r$, rata-rata persentase jawaban setuju yang diberikan oleh responden sebesar $50 \%$ dan rata-rata persentase jawaban sangat setuju sebesar 44,6\% menyatakan bahwa sistem informasi geografis ini sudah dapat mendeteksi lokasi keberadaan user, sudah mampu menampilkan informasi jarak antara lokasi user dengan lokasi kuliner sekitar, sudah dapat menampilkan rute perjalanan menuju lokasi wisata kuliner yang dipilih serta memilki tampilan yang menarik serta mudah digunakan.

\section{B. Saran}

Sistem informasi geografis pencarian lokasi wisata kuliner terdekat di kota Mataram ini masih perlu disempurnakan lagi pada pengembangan sistem selanjutnya seperti:

1) Pendaftaran lokasi wisata kuliner pada sistem dapat dilakukan sendiri oleh pengusaha wisata kuliner sehingga pengusaha kuliner dapat mengelola data lokasi kulinernya sendiri dengan persetujuan dari admin sistem.

2) Sistem informasi geografis pencarian lokasi wisata kuliner terdekat di kota Mataram ini masih berbasis wesbsite agar dapat dikembangkan menjadi berbasis mobile sehingga dapat digunakan pada Android maupun Ios.

3) Pengelompokan kategori menu kuliner untuk pencarian lokasi kuliner dapat lebih dispesifikan lagi dengan memberikan sub menu pilihan.

\section{REFERENCES}

[1] Agasa, Q., Peta Rekomendasi Pariwisata dan Kuliner Kabupaten Semarang dengan Metode Pencarian Terdekat Dijkstra. 2012.

[2] Sari, W. E., Penerapan Jquery Mobile dan Php Data Object Pada Aplikasi Pencarian Lokasi Tempat Ibadah di Yogyakarta, 2013.

[3] Arbie, Manajemen Database dengan MySQL. Yogyakarta: Andi Yogyakarta, 2002.

[4] Aryana, I. K. D., Haversine Formula Untuk Perhitungan Jarak, pp. 20-21, 2012. 